\title{
PERLINDUNGAN HUKUM BAGI ANGGOTA MULTI LEVEL MARKETING (MLM) YANG BERBASIS APLIKASI DI INDONESIA (Studi Kasus Pada PT Sukses Integritas Perkasa)
}

\author{
Dinaselina Chintya Kosasih \\ E-mail: hisasok.niles@gmail.com \\ Mahasiswa S1 Program Studi Ilmu Hukum, Fakultas Hukum, \\ Universitas Sebelas Maret Surakarta \\ Ambar Budhisulistyawati \\ E-mail: ambarbudhi@gmail.com \\ Dosen Fakultas Hukum, Universitas Sebelas Maret Surakarta
}

\begin{abstract}
This articles aims to find out about the mechanism of transactions and profit sharing at PT Sukses Integritas Perkasa and legal protection towards Multi-Level Marketing business members in case settlement during the Multi-Level Marketing business activities in the case study of PT Sukses Integritas Perkasa. This research is categorized as a descriptive empirical study. It is using a qualitative approach and primary data support and secondary data. According to the research finding, the legal protection of PT Sukses Integritas Perkasa members in case if a dispute occurs has been stated in the company code of ethics based on applicable regulations in Indonesia. The company code of ethics has elaborated the dispute resolution if a dispute occurs, whereby deliberation and consensus are prioritized prior to other resolution alternatives. In case of the deliberation and consensus failure, dispute resolution alternatives would refer to attend the third party that is arbitration based on Indonesia National Arbitrage Organization (BANI).
\end{abstract}

Keywords : Multi-Level Marketing; Legal Protection; Dispute Resolution.

\begin{abstract}
Abstrak
Artikel ini bertujuan untuk mengetahui mekanisme transaksi beserta pembagian reward dalam PT Sukses Integritas Perkasa dan perlindungan hukum bagi para anggota Multi Level Marketing tersebut beserta cara penyelesaiannya khususnya pada perusahaan MLM PT Sukses Integritas Perkasa. Penulisan hukum ini merupakan jenis penelitian hukum empiris yang bersifat deksriptif. Pendekatan penelitian menggunakan pendekatan data kualitatif dan jenis data berupa data primer serta data sekunder. Berdasarkan hasil penelitian dapat diketahui, bahwa perlindungan Hukum terhadap anggota PT Sukses Integritas Perkasa apabila terjadi perselisihan sudah tertuang dalam kode etik perusahaan yang berpedoman pada peraturan-peraturan yang sudah ada terlebih dahulu dan berlaku di Indonesia. Kode etik perusahaan juga telah menguraikan mengenai penyelesaian sengketa apabila terjadi perselisihan dimana diselesaikan secara damai terleboh dahulu yaitu dengan musyawarah dan mufakat. Pelaksanaan musyawarah dan mufakat apabila tidak menemui titik temu maka akan penyelesaian akan menggunakan alternatif penyelesaian sengketa dengan cara menghadirkan pihak ke tiga yaitu arbitrase yang berpedoman pada peraturan yang ada di Badan Arbitrase Nasional Indonesia (BANI).
\end{abstract}

Kata Kunci: Multi Level Marketing; Perlindungan Hukum; Penyelesaian Sengketa. 


\section{A. Pendahuluan}

Indonesia merupakan negara yang memiliki banyak jenis usaha. Dalam beberapa tahun belakangan ini, pertumbuhan dan perkembangan terjadi sangat cepat dibidang ekonomi. Hal tersebut ditandai dengan bertambahnya pula jenis usaha maupun strategi setiap perusahaan dalam memasarkan produknya. Tentunya setiap perusahaan memiliki tujuan, dilihat dari sudut ekonomisnya perusahaan pasti menginginkan mencari laba sebesar-besarnya dengan pengorbanan sekecil-kecilnya. Untuk itu dalam perusahaan harus ada pemusatan kekuatan ekonomis seketat-ketanya untuk mendapatkan laba sebesar-besarnya. (H.M.N.Purwosutjipto, 1999:23)

Indonesia yang merupakan negara berkembang juga tidak luput dari sasaran pembangunan untuk menjadi negara industri yang memiliki potensi pasar yang cukup besar dan luas. Hal tersebut menyebabkan terjadinya pola hubungan kerja antara produsen dengan konsumen dengan adanya mediator/perantara diantara mereka. Mediator tersebut dahulunya diisi oleh makelar dan komisioner, namun seiring dengan perkembangan kini kedudukannya digeser oleh agen dan distributor. Terjadinya perkembangan-perkembangan tersebut tentunya diikuti juga dengan pembaharuan strategi pemasarannya, oleh sebab itu mulai muncullah berbagai strategi pemasaran yang salah satunya adalah sistem pemasaran berjenjang atau sering disebut pula dengan Multi Level Marketing yang selanjutnya disebut MLM yang penjualannya dilakukan oleh jaringan distributornya sendiri

MLM ini sendiri pada awalnya ditemukan oleh dua profesor pemasaran dari Universitas Chicago kurang lebih pada tahun 1930-an. Mereka menemukan strategi sistem pemasaran tersebut dan diterapkan pada perusahaan Nutrilite Products Inc (https://www.nutrilite.com diakses tanggal 26 Oktober 2018 pukul 11.56) dimana perusahaan ini menjual produk berupa vitamin dan makanan tambahan. Sementara itu, MLM muncul di Indonesia pada tahun 1986 tepatnya di Bandung. Perusahaan yang pertama kali masuk di Indonesia itu adalah PT. Nusantara Sun Chorella

Masyarakat Indonesia cukup menyambut hangat bisnis MLM karena beberapa hal, salah satunya adalah perkembangan industri 4.0 dimana tenaga kerja manusia banyak digantikan menggunakan tenaga mesin. Perkembangan industri 4.0 ini menyebabkan banyaknya karyawan-karyawan perusahaan mengalami PHK dari perusahaan. Tanpa adanya soft skill yang mumpuni, mereka akan jauh lebih sulit untuk mendapatkan pekerjaan pengganti, sedangkan mereka juga harus tetap menjalani hidup. Adanya kendala seperti soft skill dan modal yang besar tidak berlaku dalam bisnis MLM. Dalam bisnis ini tidak memerlukan pengalaman kerja, pendidikan formal, dan modal yang besar, justru modal yang diperlukan relatif lebih kecil dibandingkan dengan bisnis konvensional.

Perkembangan industri yang memasuki era 4.0 tersebut tentunya berpengaruh juga terhadap perkembangan bisnis MLM di Indonesia khusunya. MLM yang pada awalnya bergerak dibidang penjualan barang (produk) cepat atau lambat mulai ditinggalkan karena banyak pelaku bisnis MLM ini mengalami kerugian karena tidak dapat menjualkan produknya karena harga dan barang tidak sebanding dan tidak masuk akal. Adanya perkembangan informasi dan teknologi dalam bertransaksi elektronik juga menjadikan munculnya inovasi dimana MLM yang pada awalnya hanya menjual barang tertentu (tergolong ekslusif) beralih menjual barang yang selalu digunakan setiap saat oleh seluruh orang dan sistem transaksinya pun juga mengalami pergeseran menjadi sitem online. 
Banyaknya keuntungan dan kemudahan dalam bisnis MLM ini menjadikan masyarakat Indonesia senang dan tertarik menggeluti bisnis ini, namun masyarakat Indonesia masih sering mengabaikan mengenai resiko yang mungkin dapat terjadi dalam mengikuti MLM, yang dilihat hanya keuntungan yang bisa didapatkannya. Kenyataanya perlindungan hukum di Indonesia mengenai hal tersebut masih sangat lemah dan banyak kasus yang menyebabkan kerugian khususnya bagi para anggotanya. Lemahnya produk hukum yang mengatur tentang perlindungan anggota MLM dari segi hukum tersebut sering kali menjadi celah yang sangat rentan dalam munculnya perbuatan yang dapat menimbulkan kerugian dalam kegiatan MLM.

Berdasarkan dari uraian diatas, maka dalam artikel ini akan dibahas mengenai perlindungan hukum bagi anggota MLM yang berbasis aplikasi di Indonesia dengan studi kasus pada PT Sukses Integritas Perkasa.

\section{B. Metode Penelitian}

Metode dalam penulisan skripsi ini adalah menggunakan metode penelitian hukum empiris yang menggunakan data primer dan sekunder. Sifat penelitian dalam penulisan hukum ini bersifat deskriptif, penelitian deskriptif dimaksudkan untuk memberikan data yang seteliti mungkin mengenai manusia, keadaan, atau gejala - gejala lainnya (Soerjono Soekanto, 2010:10).

Teknik analisis data menggunakan menggunakan teknik analisis data kualitatif dimana merupakan suatu cara penelitian yang menghasilkan data deskriptif yaitu apa yang dinyatakan oleh responden secara tertulis atau lisan dan perilaku nyata (Soerjono Soekanto, 2014 : 32), kemudian dihubungkan dengan teori-teori, asas-asas, dan kaidah-kaidah hukum yang diperoleh dari studi kepustakaan.

\section{Hasil Penelitian dan Pembahasan}

Pesatnya pertumbuhan MLM di dunia maupun di Indonesia menyebabkan banyaknya pula orang yang mulai tertarik dengan dunia bisnis ini. Terhitung sampai bulan Maret 2019, APLI mencatat pemain bisnis MLM ini sudah sebanyak 16 juta orang (http://www.apli.or.id diakses pada tanggal 10 Maret 2019 pukul 15:30). Tujuan dalam pengadopsiang sisem MLM adalah untuk menyebarluaskan produk serta mensejahterakan karyawan atau yang biasa disebut sebagai distributor (Siahaan, Elisabet, Prihatin L, Yasmin C, 2014: 311). Dalam MLM distributor memiliki posisi ganda, dimana dia menjadi distributor sekaligus menjadi member dalam perusahaan MLM maka harus ada perlindungan hukum yang melindungi setiap kepentingan anggota MLM tersebut agar tercapai kesejahteraan bagi para member MLM itu sendiri.

Adanya payung hukummenjadikan masyarakat semakin percaya dan yakin dalam mengikuti bisnis MLM sendiri. Peraturan-peraturan tersebut tentunya sudah berkekuatan hukum yang sah dan bersifat mengikat para pihak yang behubungan. Adapun bentuk perlindungan yang terdapat dalam peraturan-peraturan meliputi:

1. Dalam menjalankan kegiatannya, MLM harus dilakukan berdasarkan perjanjian tertulis antara perusahaan MLM dengan penjual/para anggotanya dan tunduk pada hukum Indonesia (Pasal 3 jo Pasal 6 Keputuan Menteri Perindustrian dan Perdagangan Republik Indonesia No.73/MPP/KEP/3/2000). Hal tersebut berhubungan dengan adanya syarat- 
syarat sah perjanjian yang diatur dalam Pasal 1320 jo 1347 KUHPerdata dan asas perjanjian lainnya.

2. Adanya larangan dan kewajiban bagi perusahaan MLM dalam menjalankan kegiatan bisnisnya. Hal tersebut biasanya dituangkan dalam Kode Etik Perusahaan yang didasari dengan peraturan dan hukum yang ada dan berlaku di Indonesia. Kode etik ini berguna untuk memberikan kepuasan dan perlindungan kepada smeua pihak yang berkepentingan serta untuk menerapkan kompetisi yang sehat dalam dunia usaha. (Pasal 7 dan Pasal 9 Undang-Undang Nomor 7 Tahun 2014 tentang Perdagangan).

3. Adanya Izin Usaha Penjualan Berjenjang selanjutnya disebut IUPB yang harus dimiliki setiap perusahaan MLM agar dapat menjalankan kegiatan usahanya. IUPB tersebut diberikan oleh Dirjen Perdagangan dalam Negeri dan berlaku di seluruh wilayah Indonesia dnegan jangka waktu 3 (tiga) tahun (Pasal 2 Ayat 2 Keputuan Menteri Perindustrian dan Perdagangan Republik Indonesia No.73/MPP/KEP/3/2000).

Syarat yang harus dipenuhi supaya perusahaan MLM dapat memperoleh IUPB adalah syarat administratif dan syarat non-administratif. Contoh dari syarat administratif adalah salinan akta notaris pendirian perusahaan terbatas, sedangkan contoh dari syarat nonadministratif adalah presentasi mengenai pelaksanaan bisnis MLM tersebut seperti sistem rekruitmen, jenis barang, sistem penjualan barang, dan sistem bonus/reward.

Seperti yang sudah kita ketahui bahwa perlindungan hukum bagi konsumen/para anggota MLM masih terbilang sangat lemah. Di Indonesia sendiri belum ada peraturan yang concern dan khusus mengatur mengenai MLM. Belum adanya peraturan yang khusus mengatur mengenai MLM ini bukanlah halangan bagi para pelaku bisnis MLM. Pengaturan MLM hanya diatur dalam Keputusan Menteri Nomor 73/MPP/KEP/3/2000 padahal peraturan tersebut memiliki jangkauan yang terbatas. Selain itu lemahnya pemberian sanksi terhadap perusahaan MLM yang melakukan pelanggaran juga menjadikan perlindungan hukum terhadap anggota ini semakin buruk dan yang cukup berpengaruh adalah sistem perizian yang lemah menyebabkan banyaknya perusahaan yang berkedok MLM mudah untuk lolos dan berkembang di masyarakat.

PT Sukses Integritas Perkasa adalah salah satu perusahaan MLM yang bernaung dibawah naungan APLI, oleh sebab itu PT SIP dalam perjalanannya juga menjadikan kode etik APLI sebagai acuan. Hal-hal dasar yang terdapat dalam kode etik APLI tersebut mengatur tentang kepatuhan penjualan langsung, perekrutan, informasi bisnis, remunerasi dan pelaporan, pernyataan penghasilan, hubungan, iuran. Pemutusan hubungan, persediaan produk, materimateri lainnya, dan pelatihan bagi penjualan langsung.

Selain adanya aturan mengenai penjualan langsung, APLI juga mengatur mengenai perlindungan konsumen dalam praktek pelaksanaan bisnis MLM tersebut. Perlindugan hukum bagi konsumen tesbut terdapat dalam Pasal 2 Kode Etik APLI. Apabila terjadi penyimpangan dari kode etik APLI maupun kode etik perusahaan (PT SIP) maka dapat disimpulkan terjadi perselisihan.

Kode etik APLI memuat pengaturan yang digunakan untuk melindungi konsumen (member/annggota). Pengaturan tersebut tercantum dalam pasal yang kedua, dimana dalam pasal tersebut mengatur mengenai praktek-praktek terlarang, idnetifikasi, penjelasaan dan pearagaan, formulir pemesanan, literatur, kesaksian, perbandingan dan pencemaran, masa 
tenang dan pengembalian barang, penghormatan pada hak pribadi, kewajaran/keaadilan, penjualan referal, dan pengiriman baraang.

MLM yang merupakan kegiatan usaha direct selling dilarang menggunakan praktekpraktek penjualan yang bersifat menyesatkan, menipu, atau tidak jujur. Pada awal presentasi penjualan, penjual wajib dengan jujur dan jelas untuk memperkenalkan diri mereka, identitas peusahaan mereka, produk mereka, dan tujuan pertemuan/berkumpulnya mereka kepada para calon konsumen/anggota. Penjelasan dan peragaan produk secara lengkap dan akurat sangat dibutuhkan agar konsumen dapat mengerti betul keseluruhan mengenai produk yang dipasarkan. Hal yang harus dijelaskan oleh penjual kepada calon konsumen adalah harga, kondisi barang dan jika ada, syarat-syarat kredit; syarat pembayaran; masa tenang, termasuk kebijakan pengembalian, syarat-syarat jaminan; layanan purna jual; dan tanggal pengiriman/ pengantaran.

Pendaftaran sebagai member MLM harus menggunakan formulir pendaftaran, hal tersebut sama halnya dengan ketentuan mengenai formulir pemesanan dimana harus dalam bentuk yang tertulis dan mencantumkan identitas kedua belah pihak. Promosi ataupun iklan dan penawaran mengenai barang tidak boleh memuat keterangan, pernyataan, foto ataupun ilustrasi produk yang bersifat mengecoh, menipu, maupun menyesatkan. Literatur promosi harus berisikan nama dan alamat atau nomor telepon perusahaan dan dapat juga mencakup nomor telepon penjual. Perusahaan dan Penjual Langsung tidak boleh menggunakan perbandingan yang menyesatka atau kesaksian maupun dukungan dalam bentuk apapun yang dinyatakan tidak benar, atau yang tidak dapat diterapkan lagi, yang tidak berkaitan dengan penawaran atau yang dipergunakan dengan cara yang dapat menyesatkan Konsumen.

Perusahaan dan Penjual Langsung harus menawarkan suatu masa tenang yang memungkinkan pelanggan membatalkan pesanannya dalam jangka waktu tertentu yang telah ditetapkan dan masuk akal. Masa tenang harus dinyatakan dengan jelas. Perusahaan dan Penjual Langsung yang menawarkan hak untuk pengembalian, baik dengan persyaratan atau tidak, harus melakukannya secara tertulis, hal tersebut juga diterpkan dalam PT SIP. Perusahaan ini juga mengatur mengenai masa tenggang waktu yaitu 10 (sepuluh) hari sejak tanggalpembelian dengan syarat-syarat yang telah ditentukan oleh perusahaan. Pengembalian barang dapat dilakukan apablia barang yang datang tidak layak konsumsi, rusak, atau cacat. Selain itu pengembalian barang juga dapat dilakukan apabila terjadi pengakhiran kemitrausahaan dengan perusahaan (dengan catatan barang masih layak jual kembali).

PT Sukses Integritas Perkasa yang merupakan perusahaan MLM tentunya juga memiliki peraturan untuk mengatur mengenai penyelesaian sengketa apabila ada pihak yang melakukan tindakan yang merugikan antara perusahaan dengan para anggotanya. Upaya dalam penyelesaian sengketa antara perusahaan dengan para anggotanya apabila terjadi perbuatan melawan hukum tersebut tentunya sangat diutamakan dengan melalui jalur damai dan kekeluargaan dengan cara musyawarah dan mufakat.

Musyawarah dan mufakat lebih diprioritaskan dengan tujuan untuk mempertahankan sistem marketing agar para anggota tetap menjadi anggota aktif dan merasa nyaman dalam hal jalur penyelesaian sengketa akibat perbuatan melawan hukum / tindakan yang merugikan. Selain itu, cara musyawarah dan mufakat juga dianggap cukup efektif karena langsung mempertemukan kedua belah pihak yang berselisih serta tidak diperlukan biaya yang tinggi. 
Adapun alasan lain musyawarah dan mufakat lebih diminati karena waktu penyelesaian sengketa relatif lebih singkat sebab para pihak dapat langsung membahas pokok permasalahan tanpa ada aturan hukum acara persidangan. Pertimbangan yang paling utama dari penyelesaian perselisihan secara internal karena terjaganya kerahasiaan perusahaan sehingga kredibilitas dan nama baik perusahaan tetap terjaga.

Penerapan standart kode etik pada perusahaan MLM merupakan salah satu cara yang digunakan untuk menyelesaikan perselisihan salah satunya akibat penyimpangan kewajiban salah satu pihak. Kode etik tersebut pada dasarnya berisikan nilai-nilai normatif yang wajib dipenuhi dan dilaksanakan serta dipatuhi oleh setiap anggotanya. Kode etik merupakan kesepakatan bersama yang menyatukan visi dan menjadi aturan bersama dalam dalam suatu jaringan. Inti dari kode etik sebenarnya hampir sama dengan Undang-Undang bagi para anggotanya, oleh sebab itu kode etik ini bersifat mutlak.

Apabila perselisihan, pertentangan, atau perbedaan yang dimaksud tidak dapat diselesaikan secara musyawarah dalam waktu 60 (enam puluh) hari setelah pemberitahuan dari satu pihak ke pihak lain maka peselisihan yang terjadi karena perbuatan melawan hukum maupun tindakan yang merugikan yang berhubungan dengan kode etik ataupun pelaksanaannya harus diselesaikan secara arbitrase oleh 3 (tiga) orang anggota dewan arbitrase, yang akan bersidang di Jakarta dalam Bahasa Indonesia dengan menggunakan Peraturan BANI (Badan Arbitrase Nasional Indonesia) (Kode Etik dan Peraturan Perusahaan, 2017:20).

\section{Simpulan}

Perlindungan terhadap anggota PT Sukses Integritas Perkasa sudah diatur dalam kode etik perusahaan dan merujuk kepada peratura-peraturan yang telah ada yang berlaku di Indonesia. Apabila terjadi sengketa dalam pelaksanaannya dan merugikan pihak anggota maka penyelesaian yang diambil adalah menggunakan jalur damai yaitu musyawarah dan mufakat. Namun apabila dalam 60 (enam puluh) hari setelah musyawarah dan mufakat dilakukan tidak berhasil menyelesaikan masalah yang terjadi, maka penyelesaiannya menggunakan bantuan pihak ke tiga yaitu menggunakan alternatif pnyelesaian sengketa. Alternatif penyelesaian sengketa yang dipilih adalah melaluli jalur Arbitrase dan menggunakan peraturan sesuai dengan ketentuan Badan Arbitrase Nasional Indonesia (BANI) dan putusannya bersifat final dan mengikat kedua belah pihak. Peraturan arbitrase sendiri diatur dalam Undang-Undang Nomor 30 Tahnu 1999 tentang Arbitrase dan Alternatif Penyelesaian Sengketa. Penyelesaian sengketa yang terjadi akibat perbuatan melawan hukum dalam PT SIP selain berdasarkan kode etik perusahaan dan UU Nomor 30 Tahun 1999 juga menganut peraturan dan kode etik dari Asosiasi Penjualan Langsung Indonesia (APLI) yang tentunya sudah menjamin tentang perlindungan anggota MLM itu sendiri.

\section{E. Saran}

Pihak PT Sukses Integritas Perkasa perlu memperhatikan kesejahteraan dan jaminan rasa aman setiap anggota/membernya dengan cara mengeluarkan peraturan yang jelas dan terperinci serta mudah untuk dipahami, selain itu perusahaan juga harus meningkatkan sistem yang sudah ada kearah yang lebih baik sehingga selain merasa aman, para anggota menjadi lebih semangat dan aktif dalam pelaksanaan bisnis MLM ini dan dalam pelaksanaanya setiap 
pelaku usaha ini (perusahaan dan anggota/member) juga harus menaati setiap peraturan yang telah disetujui bersama agar tidak terjadi tindakan yang merugikan salah satu pihak.

\section{F. Daftar Pustaka}

PT Sukses Integritas Perkasa. 2017. Kode Etik dan Peraturan Perusahaan. Jakarta : Smart Academy.

Soerjono Soekanto.2010.Pengantar Penelitian Hukum. Jakarta: Gramedia PustakaUtama. .2014. Penelitian Hukum Normatif Suatu Tinjauan Singkat. Jakarta: Rajawali Pers.

Ah. Hifni, Muhammad Mansur, Agus Priyono.2017.’Pengaruh Reward, Punishment,dan Motivasi Terhadap Kinerja Karyawan (Pabrik Gula Krebet PT PG Rajawali I Malang)”. JEMA:Jurnal Ilmiah Bidang Akutansi dan Manajmen Malang: FE UNISMA.

Ahmad Mardalis dan Nur Hasanah. 2016. "Multi Level Marketing (MLM) Prespektif Ekonomi Islam”. Benefit.Vol 1, No. 1, 2016. Sekolah Pasca Sarjana . Surakarta: UMS.

Alfiana Prayutasani, Rinitami Njatrijani, dan Suradi. 2016. "Perlindungan Hukum Atas Kegiatan Usaha MLM (Multi Level marketing) Studi Pada Rumah Avail Semarang”. Diponegoro Law Review. Vol 5, No. 2. 2016. Semarang: FH UNDIP.

Anita Rahmawaty. 2014. "Bisnis Multi Level Marketing dalam Prespektif Islam". Libraria. Vol 2, No. 1, 2014. Kudus: STAIN KUDUS.

Cahn, P.S. 2008. "Consuming Glass: Multilevel Marketers in Noliberal Mexico”. Cultural Antropology, Proquest.

Retno Andriati. 2015. "Manipulative Cooperation Politics of MLM Companies In Surabaya City". Humaniora Vol 27, No. 2. 2015. Yogyakarta: FIB UGM.

Ros Angesti Anas Kapindha, Salvatia Dwi M, dan Winda Rizky Febrina.2014. "Efektivitas dan Efisiensi Altenative Dispute Resolution (ADR) Sebagai Salah Satu Penyelesaian Sengketa Bisnis di Indonesia”. Privat Law. 1 Vol 2, No.4. Surakarta: FH UNS.

Siahaan, Elisabet, Prihatin Lumbanraja, Yasmin Chairunisa. 2014. "A Career Succsess of the Company in Information of Management Business Riview". LP-International Published Articles Vol.6, No. 6. Sumatera Utara

Siti Zulaeha.2017. "Insentif Passive Income pada Multi Level Marketing Syariah di Mulia Artha Qives Jakarta Dalam Perspektif Fiqh Muamalah". I-Economics: A Research Journal on Islamic Economics.Palembang:UIN Raden Fatah.

Virnia Ratih Lovita Dewi Adilang, Riane J. Pio, Sandra Asaolei. 2018. "Persepsi Karyawan Tentang Kode Etik Perusahaan". JAB:Jurnal Administrasi Bisnis. Vol. 6 No. 2. Manado: Universitas Sam Ratulangi. 
Dinaselina Chintya Kosasih, Ambar Budhisulistyawati. Perlindungan Hukum bagi Anggota Multi Level ...

\section{Kitab Undang-Undang Hukum Perdata}

Undang - Undang Nomor 7 Tahun 2014 tentang Perdagangan

Undang-Undang Nomor 30 Tahun 1999 tentang Arbitrase dan Penyelesaian Sengketa

Keputusan Menteri Perindustrian dan Perdagangan No. 73 /MPP/Kep 13/2000 tentang Ketentuan Kegiatan Usaha Penjualan Berjenjang

http://www.apli.or.id diakses pada tanggal 10 Maret 2019 pukul 15:30

https://www.nutrilite.com diakses tanggal 26 Oktober 2018 pukul 11.56 